\title{
Parents - their changing role in developing talent for sport
}

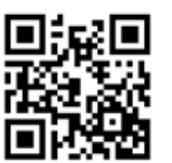

One thing almost all parents have in common is the desire to ensure the well-being of their children. This translates into protecting them from adversity while at the same time trying to give them skills that make them successful adults. Most parents would like to see their children grow up to be financially independent, happy and contributing to society. Among these are also parents who would like to see their children grow up to become sporting superstars. What is the best style of parenting to achieve these goals?

Many athletes performing at the highest level have acquired the skills they need through adversity. Given that there is some truth to this statement, what is the role of parents? This topic was discussed at the recent Youth and Talent Identification and Development Conference in Cape Town. A keynote speaker, Dr Joe Baker of York University, Canada, raised awareness of the changing role of parents in supporting children in their quest to develop their athletic talent. During the foundation phase of development, the support from the parents is mostly financial. Parents with greater means can support their children and give them more opportunities than parents from poorer backgrounds. He discussed the 'sampling phase' where the child experiences a variety of sports and the support of parents continues to be financial and emotional. During this phase the parents are also important role models for the child. During the specialising phase, which coincides with adolescence, the role of the parent is mostly financial. The message is clear; the main role of the parent is through the financial support in the early years of development, enabling the child to experience a variety of sports, good coaching, access to facilities and competition. This should ring alarm bells in South Africa where the children from poorer households are not going to have the same experiences as children from more affluent homes and therefore are less likely to develop their talent fully. Dr Baker addressed this by saying that although socioeconomic status had an impact on 'opening the door, once the door was open it does not have a major effect on the development of talent'. In a society such as ours, with vastly uneven playing fields, the state has a responsibility to narrow the socioeconomic status gap. Sporting federations also have a responsibility to create opportunities for children to play and compete that are not dependent on the wealth of the parents.

Dr Baker also showed that elite athletes are more likely to be laterborn children in a family, while non-elite athletes are more likely to be first-born children. ${ }^{[1]}$ Although this was a descriptive study, it opens up interesting possibilities for factors contributing to the development of talent.
Another point made at the conference was the almost nonexistent chance of a young player with sporting talent converting into a high-level professional player. For example, of the 5 - 8 million youth playing basketball in the USA, only 15 - 20 progress to play National Basketball Association level basketball. In South Africa, only $0.02 \%$ of under- 18 rugby players go on to become Springboks. ${ }^{[2]}$ To make a visual impression of this statistic, if Newland's stadium was full (about 40000 people) of under- 18 rugby players, only 7 in the stadium would go on to become Springboks!

So my take-home message from the conference was that there is no simple formula for identifying and developing talent. Parents have a role to play in supporting their children, but this role should mostly be in the background, supporting and paying the bills. Adversity is not a problem and can develop important skills that are a prerequisite for success at a high level. However, this is tricky for it is not in the nature of parents to welcome adversity into the lives of their children. The next point from the conference was that children should have the opportunity to sample many sports, but if they come from a poorer environment and do not have other opportunities, then playing only one sport at an early age is a viable option for developing talent. Competition that encourages winning-at-all-costs at young ages should be discouraged. Failure to do so will compromise skill development and progression for all children - the children who mature early will have an advantage - the children who mature later will be disadvantaged and lost to the system. The most important message for parents was to act as good role models and teach children the importance of physical activity. These lessons, taught well, will have a meaningful impact on how our children grow and incorporate physical activity into their lifestyles. This is surely a noble outcome.

\footnotetext{
1. Hopwood MJ, Farrow D, MacMahon C, Baker JJ Sibling dynamics and sport expertise. Scand J Med Sci Sports 2015 (in press).

2. Parker Z. Factors associated with success in South African Rugby Union. MPhil thesis. Cape Town: University of Cape Town, 2013.
}

\section{Mike Lambert}

Editor-in-chief

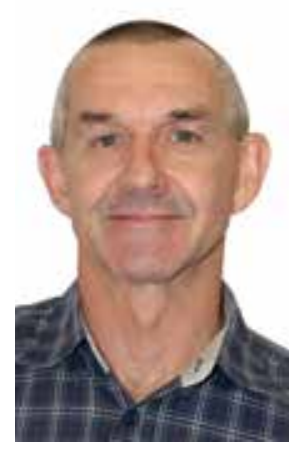

S Afr J Sports Med 2015;27(2):27. DOI:10.7196/SAJSM.634 